\title{
LOS SISTEMAS DE PARTICIPACION DE LAS ENTIDADES SUBESTATALES EN LA FORMACION Y EJECUCION DEL DERECHO COMUNITARIO
}

\author{
POR \\ Antonio Calonge Velázouez \\ Profesor Titular de Derecho Administrativo
}

\begin{abstract}
Sumario: I. Planteamiento.-II. La República federal de Alemania: Un sistema pRevisto en la Ley. - III. La República de Italia: una aspiracion insatisfecha. - IV. El Reino de Bélgica: un sistema de participación no institucionalizado.-V. El Reino de España: INTENTOS Y PROYECTOS: 1. Los proyectos de convenios de cooperación entre el Gobierno de la Nación y las Comuniddes Autónomas sobre los asuntos relacionados con las Comunidades Europeas. 2. Algunos instrumentos más de participación. 3. Recapitulación.
\end{abstract}

\section{PLANTEAMIENTO}

Resulta de todos conocido que una de las aspiraciones de los poderes públicos internos (Ilámense Länder, Regiones o Comunidades Autónomas) de los Estados miembros de la Comunidad Económica Europea que tienen una estructura plural o compuesta, es la de participar en la formación y en la ejecución del Derecho comunitario; aspiración, a mi juicio, razonable y lógica a todas las luces aunque sólo sea por el hecho (ya suficientemente importante, en mi opinión) de que se trata de un ordenamiento jurídico que incide clara y notoriamente en el ámbito competencial propio de estos entes subestatales. En algún momento, incluso, se llegó a pensar si la perteneciente de este tipo de Estados a la Comunidad Económica Europea no podría conllevar una redistribución del poder.

La Comunidad Europea, en aras del llamado por la doctrina (1) principio de autonomía institucional de los Estados miembros o principio de la indiferencia del Derecho comunitario hacia la estructura institucional interna de los Estados miembros, no prejuzga a qué instancia política corresponde el cumplimiento de las obligaciones comunitarias dentro de un Estado miembro, ni mucho menos cómo deben formar su voluntad los Estados para la creación del Derecho comunitario o la formación de las políticas de las Comunidades

(1) Así lo señala el profesor JEAN-VICTOR LouIs en su trabajo «Quelques reflexions sur l'execution du Droit communautaire en Belgiquem, en La collaboration del l'Etat, des Communautés et des Regions dans le domaine de la politique exterieure, dirigido por los profesores Francis Delpérée e Yves Lejeune, Academia, Bruxelles, 1987, p. 134. 
Europeas (2). Son estas cuestiones que cada Estado debe decidir de acuerdo con su Derecho interno.

Ahora bien, debe subrayarse que esta libertad de los Estados miembros tiene unos límites que derivan de la necesidad de asegurar la uniformidad, la primacía y la aplicabilidad directa del Derecho comunitario. A este respecto, el artículo 5.1 del Tratado constitutivo de la Comunidad Económica Europea de 25 de marzo de 1957 es tajante cuando instituye una obligación formal a los Estados miembros de poner en marcha un sistema que asegure el respeto a los mencionados objetivos. El citado precepto es del siguiente tenor literal:

«Los Estados miembros adoptarán todas las medidas generales o particulares apropiadas para el cumplimiento de las obligaciones derivadas del presente Tratado o resultantes de los actos de las instituciones de la Comunidad. Facilitarán a esta última el cumplimiento de su misión.»

En nuestro país también las Comunidades Autónomas aspiran a participar en la formación y ejecución del Derecho comunitario. En este sentido se han pronunciado los distintos grupos políticos con representación parlamentaria en el debate sobre «el estado de las Autonomías» celebrado al año siguiente de nuestra incorporación a la Comunidad Económica Europea (3). Y, ya con anterioridad a nuestra incorporación, la doctrina se había ocupado y preoucpado del tema (4). Asimismo, de continuo se alzan las voces de los Presidentes y representantes de las Comunidades Autónomas reclamando un derecho de participación, al menos, en los asuntos comunitarios que afectan a las Comunidades Autónomas. Asistimos, pues, en el momento presente, como ha dicho Montoro Chiner, «a la queja generalizada de las Comunidades Autónomas sobre su participación en el proceso de la formación de la voluntad estatal expresada ante las Comunidades Europeas» (5).

(2) El Tribunal de las Comunidades Europeas, entre otras, en su Sentencia Comisión, v. Países Bajos de 25 de mayo de 1982 (asunto núm. 97/81, Recueil 1982-5, p. 1833) ha manifestado: «ll est vrai chaque Etat memebre est libre de répartir comme il juge opportun les compétences sur le plan interne et de mettre en oeuvre une directive au moyen de mesures prises par les autorités regionales ou locales...».

(3) Vid. Diarios de Sesiones del Senado núms. 55 y 56 de 1987, p. 2104 y ss

(4) Antes de la incorporación de España a la Comunidad Europea puede verse: Constitución, Comunidades Autónomas y Derecho internacional, Xunta de Galicia Santiago, 1982 y la integración de España en las Comunidades Europeas y las competencias de las Comunidades Autónomas, Generalitat de Catalunya, Barcelona, 1985.

(5) Montoro Chiner, M. a Jesús: «La Ley alemana de ratificación del Acta Unica Europea de 19 de diciembre de 1986 y la participación de los Länder en la formación de decisiones comunitarias». REDA, núm. 55, julio-septiembre, 1987, p. 371. 
Expuesto esto, estimo necesario y conveniente que acudamos al Derecho comparado, a la experiencia de otros Estados miembros que, como el nuestro, tienen una forma compuesta - ya sea federal o regional-, y analicemos qué soluciones han adoptado para solventar esta cuestión; cómo han respondido a esta aspiración, a este deseo de los poderes públicos internos de participar en el Derecho comunitario. Nos detendremos en tres casos, a mi juicio, suficientemente representativos: la República Federal de Alemania, la República de Italia y el Reino de Bélgica. A buen seguro de lo actuado por estos países - viejos miembros de la Comunidad Europea- algunos datos, algunas soluciones útiles podremos extraer para la cuestión que aquí nos hemos planteado: la participación de las Comunidades Autónomas en el Derecho comunitario. No se trata de aplicar sin más la experiencia de estos países al nuestro; esto sería peligroso además de poco eficaz. Como ha manifestado CIAvarinI (6), los Estados regionalizados deben organizar de manera eficaz su participación en la vida comunitaria.

Pero antes de adentrarnos en el trabajo debemos constar dos puntualizaciones: la primera es que en la presente exposición no vamos a referirnos al tema de las relaciones entre Comunidades Autónomas y Derecho internacional, cuestión ésta, en mi opinión, suficientemente tratada por la doctrina española (7); y, segunda, que en el proceso de participación de los entes autónomos en el Derecho comunitario debemos distinguir dos fases: una denominada «ascendente", que hace referencia a la participación en la formación del ordenamiento jurídico y las políticas comunitarias, y otra «descendente» que se refiere a la participación en la ejecución, ya sea normativa o meramente administrativa, del aludido ordenamiento jurídico.

Pues bien, comencemos analizando las soluciones y los sistemas seguidos por los viejos Estados miembros mencionados más arriba y. seguidamente, analicemos cuál es el status quaestionis en nuestro país, así como los distintos instrumentos de que dispone nuestro ordenamiento jurídico interno para conseguir que ese deseo de las Comunidades Autónomas de participar en el Derecho comunitario pueda convertirse en una eficaz realidad.

(6) Ciavarini Azzi, Giuseppe: aL'application du droit, communautaire dans les Etats membres: une vue d'ensemble», Revue française d'Administration publique, núm. 34 avril-juin, 1985, p. 200

(7) Vid., entre otros, Remiro Brotons, Antonio: «La actividad exterior del Estado y las Comunidades Autónomasì, en Estudios sobre la Constitución española de 1978, Pórtico, Zaragoza, 1979, pp. 333-377 y Mangas Martin, Araceli: «Derecho comunitario europeo y Derecho español», Tecnos, Madrid, 1986, especialmente p. 206 y ss. Además de los citados en nota 4 y Jauregui Bereciartu, Gurutz: «Las Comunidades Autónomas y las relaciones internacionales», IVAP, Oñati, 1986. 


\section{LA REPUBLICA FEDERAL DE ALEMANIA: UN SISTEMA PREVISTO EN LA LEY}

La participación de los Länder en la formación del Derecho comunitario se encuentra articulada, actualmente, en la Ley de ratificación del Acta Unica Europea de 19 de diciembre de 1986.

Los Länder temían, como ha señalado George Ress (8), una pérdida de competencias de diversas materias con motivo de la implantación del Acta Unica Europea y aprovecharon el momento de la ratificación de este nuevo Tratado integrante del llamado derecho originario para presionar en favor de modificaciones en la distribución competencial en materia de política europea entre ellos y la Federación. Para ser aprobada esta Ley hubieron, por tanto, de solventar las dificultades surgidas por razón de las relaciones Federación-Länder.

En esta Ley de 19 de diciembre de 1986, concretamente en su artículo 2, que es el más importante a los efectos que nos ocupan, ya que los otros dos se limitan a ratificar el Acta (art. 1) y a estabecer la cláusula de vigencia para el Land de Berlín (art. 3), se establece el siguiente procedimiento de participación de los Länder en la formación de la voluntad de la Federación (9):

1.- El Gobierno federal, sin perjuicio del artículo 2 de la Ley sobre los Tratados de 25 de marzo de 1957 para la Constitución de la Comunidad Económica Europea y de 27 de julio de 1957 para la de la Comunidad Europea de la Energía Atómica, informará detalladamente: y lo más pronto posible al Consejo federal sobre todos los proyectós que, en el marco de la Comunidad Europea, pudieran ser de interés para los Länder.

2.․ El Gobierno federal otorga al Consejo federal, dentro de un plazo adecuado, ocasión para la toma de posición antes de dar su conformidad a acuerdos de las Comunidades Europeas, que, en su totalidad o en alguna de sus determinaciones, afecten a materias de la competencia legislativa exclusiva de los Länder o que afecten a sus intereses esenciales.

3. - El Gobierno federal tiene en cuenta este parecer de los Länder en las negociaciones. En la medida en que una toma de posición afecte a materias de la competencia legislativa exclusiva de los Länder, el Gobierno federal sólo puede apartarse de la misma por motivos incontestables de política exterior o de la integración

(8) Ress, George: «La Ley alemana de ratificación del Acta Unica Europea: un paso hacia la "federalización" de la política europea», REALA, núm. 237, enero-marzo, 1988, p. 928.

(9) He seguido las traducciones ofrecidas en Montoro CHINER, M. J.: «La ley alemana ...", cit., y RESS, G., op. cit. 
europea. A excepción de lo anterior, habrá de tener en cuenta los intereses de los Länder recogidos por el Consejo federal.

4. En el supuesto de un apartamiento de la toma de posición del Consejo federal en relación con una materia de la competencia legislativa exclusiva de los Länder y, en todo caso, siempre que se le solicite, el Gobierno federal comunica al Consejo federal los motivos determinantes del mismo.

5. - Siempre que proceda dar ocasión al Consejo federal para una toma de posición, deben, a solicitud y sin perjuicio de las regulaciones ya existentes, incorporarse repreentantes de los Länder a las negociaciones en los órganos consultivos de la Comisión y del Consejo en la medida en que ello le sea posible al Gobierno federal.

6. - Se reserva a un convenio a suscribir entre la Federación y los Länder los detalles sobre la información y la participación (10).

Este es, pues, esquemáticamente expuesto, el procedimiento de participación de los Länder en la formación de las decisiones comunitarias, tanto en las que afectan a sus competencias legislativas exclusivas como en aquellas que afectan tan sólo a sus intereses.

Pero para llegar a este procedimiento de participación, hoy previsto en una Ley, ha sido preciso recorrer todo un largo camino no exento de obstáculos y conflictos entre la Federación y los Länder, que se inició con el Acuerdo de Lindau de 1957 y que, pasando por el Acuerdo de 1979, ha culminado en esta Ley de ratificación del Acta Unica Europea de 19 de diciembre de 1986 (11).

Del procedimiento de participación descrito hay que destacar sobre todo que la participación de los Länder se articula a través del Consejo federal y no directamente por los propios Länder como ocurría después del Acuerdo de 1979. Es éste un procedimiento, en mi opinión, mucho más realista y positivo que el anterior, complejo y complicado que hacía prácticamente imposible llegar a una decisión conjunta de los Länder. Baste señalar como dato probatorio de lo dicho, que de los 1.000 proyectos comunitarios transmitidos por la Federación a los Länder durante el período 1980-1986, tan sólo 37 han contado con una posición conjunta de los Länder (12).

(10) El Gobierno federal y el Gobierno de los Länder ya han suscrito el Convenio previsto en el artículo 2.6 de la Ley de ratificación del Acta Unica Europea de 19 de diciembre de 1986. El texto de este Convenio puede verse en el trabajo citado de RESs, G., como addenda, «La Ley alemana ...», cit., p. 947 y ss.

(11) Un amplio análisis del camino recorrido por los Länder puede verse en Morawirz, Rudolf, La colaboración entre el Estado y los entes autonómicos territoriales en la Comunidad Europea, Civitas, Madrid, 1985, traducción y notas de Antonio Jiménez Blanco.

(12) Tomo el dato de Montoro Chiner, M. J.: «La Ley alemana ...», cit., p. 376 y nota 8. 
Además, en el procedimiento anterior previsto (el Acuerdo de 1979) se requería la unanimidad en la opinión de los Länder, unanimidad casi imposible de alcanzar, mientras que en el ahora vigente, al articularse la participación de los Länder a través del Consejo federal, esta regla de la unanimidad ha sido sustituida por la mayoría, incontestablemente, cuando menos, mucho más operativa, sino también más democrática.

Efectivamente, con el establecimiento de este sistema los Länder se han asegurado su participación en la formación de la voluntad de la Federación en la toma de decisiones comunitarias. $Y$, lo que es mucho más importante, se han asegurado, a mi modo de ver, que su opinión sea tenida en cuenta de manera importante en todos aquellos asuntos que afectan a sus intereses. Aunque bien es verdad que esta Ley no está exenta de problemas en cuanto a su constitucionalidad (13), lo cierto es que el sistema parece operativo y eficaz.

Por lo que hace referencia al segundo aspecto de la cuestión, es decir, a la participación de los Länder en la ejecución del Derecho comunitario, la regla que se sigue es, como ha señalado Pérez TREMPS (14), la de respetar el sistema de distribución de competencias establecido en la Ley Fundamental de Bonn (15), de tal manera que la ejecución del ordenamiento jurídico comunitario, ya sea normativa o administrativamente, la realice quien ostente la competencia sobre la materia, que, en atención al sistema constitucionalmente previsto, será en la práctica totalidad de los supuestos el Land.

Subrayemos que en aquellos supuestos en que un Land incumpla las obligaciones comunitarias, la Federación no dispone de ningún poder de sustitución, como veremos sí tiene la República de Italia, para hacer cumplir lo dispuesto por las Instituciones de las Comunidades Europeas, salvo el sistema de coacción federal regulado en el artículo 37 de la Ley Fundamental de Bonn.

Finalmente, aún podemos siquiera sea solamente enunciar otros instrumentos de participación, de presencia de los Länder en las Comunidades Europeas, como es el caso del llamado «observador de los Länder», figura designada por éstos para tener una mayor y más directa información de los asuntos comunitarios que afectan a sus intereses, que se incardina dentro de la Representación Permanente de la República Federal Alemana; la incorporación de representantes

(13) Sobre los problemas de constitucionalidad de la Ley de ratificación. Vid. MONTORO Chiner, M. J.: «La Ley alemana ...», cit., pp. 377-379.

(14) Perez Tremps, Pablo: Comunidades Autónomas, Estado y Comunidad Europea, Ministerio de Justicia, Madrid, 1987, p. 44.

(15) Sobre el sistema de distribución de competencias entre la Federación y los Länder en la Ley Fundamental de Bonn. Vid. AlBertı Rovira, Enoch: Federalismo y cooperación en la República Federal Alemana, CEC, Madrid, 1986, especialmente pp. 75-104. 
de los Länder en las delegaciones de la Federación contactos directos entre las autoridades de los Länder y las comunitarias, aunque eso sí, bajo control federal.

\section{LA REPUBLICA DE ITALIA: UNA ASPIRACION INSATISFECHA}

Las soluciones ofrecidas por el legislador italiano para satisfacer las aspiraciones de participación de las Regiones en la formación y ejecución del Derecho comunitario han sido muy distintas a las que hemos visto para el caso de la República Federal de Alemania. No podría ser de otra forma. Italia no es un Estado de tipo federal, como resulta por todos sabido, sino regional, por lo que sus presupuestos son diferentes.

Como ha manifestado Onorato Sepe (16), el problema de las relaciones entre las Regiones italianas y la Comunidad Europea no pueden ser tratados más que en el cuadro del proceso lento que ha caracterizado el nacimiento de las Regiones en Italia. Efectivamente, así es. Hasta que no aparecen las Regiones llamadas de «autonomía ordinaria», es decir, hasta que finalmente el país no se regionaliza realmente, el problema de las relaciones entre las Regiones y la Comunidad Europea apenas se plantea.

Es más, hasta el año 1977 se negaba a las Regiones no sólo su participación en la formación del Derecho comunitario, en la denominada fase «ascendente», sino incluso en la fase «descendente», esto es, de ejecución del ordenamiento jurídico comunitario. Este criterio, intransigentemente centralista (17), lo justificaba la Corte Costituzionale, entre otras, en su sentencia 46/1961, de 11 de julio, en la exclusividad que la Constitución otorgaba al Estado en materia de relaciones internacionales, lo que significaba que el Estado era el único responsable de las obligaciones contraídas hacia el exterior, aunque ello supusiera una alteración del sistema de distribución de competencias establecido en el texto constitucional.

La situación descrita variará a partir del año 1977, como tendremos ocasión de exponer, por lo menos en lo que hace referencia a la ejecución de la normativa comunitaria, no así por lo que respecta a la denominada fase «ascendente».

Las aspiraciones de las Regiones a participar en la formación del Derecho comunitario se han hecho sentir en numerosas ocasiones,

(16) SePE, Onorato: «La relación entre las Regiones italianas y las Comunidades Europeas: las instituciones y la organización», D. A., núm. 198, abril-junio, 1983, p. 19.

(17) LAPERgola, ANTONIO: «Autonomía regional y ejecución de las obligaciones comunitarias». REDC, núm. 13, enero-abril, 1985, p. 9. 
pero hasta el momento apenas se han visto satisfechas por el Estado. De este modo, por ejemplo, las Regiones han presentado distintos proyectos de ley estableciendo un procedimiento para que fueran oídas y atendidas sus opiniones sobre las decisiones comunitarias que afectasen a sus intereses; proyectos de ley que, por supuesto, no han sido tomados en consideración por la Cámara legislativa (18).

Sin embargo, las presiones regionales no han dejado de producirse y algunos resultados, modestos, pero interesantes, como dice Condorelli (19), se han conseguido. Así, por Decreto del Presidente del Consejo de 12 de octubre de 1983 se ha creado una Conferencia Estado-Regiones que puede ser consultada, entre otras cuestiones, en lo que se refiere a «las orientaciones generales relativas a la elaboración y ejecución de actos relacionados con competencias regionales».

Podemos, pues, concluir por lo que respecta a esta fase que las Regiones al menos formalmente - otra cosa es la picaresca realidad italiana-, apenas participan en la formación del ordenamiento jurídico comunitario o de las políticas comunitarias. Solamente son consultadas. Las Regiones no se contentan con esto y aspiran, como parece lógico, a desempeñar un papel más protagonista.

Por lo que repecta al segundo aspecto de la cuestión, esto es, a la fase «descendente», como hace un momento anunciábamos, el panorama cambia sustancialmente a partir del año 1977. Concretamente, el cambio se produce con la promulgación del famoso Decreto de la Presidencia de la República (DPR) número 616, de 24 de julio, producto de la Ley número 382, de 22 de julio de 1975, sobre el ordenamiento regional y la organización de la Administración pública.

No obstante, antes de examinar lo dispuesto en el citado Decreto por el legislador italiano, debemos reseñar que ya en el año 1972 , con motivo del dictado de los 11 Decretos de transferencia a las Regiones de la competencia en las materias indicadas en el artículo 117 de la Constitución que mantenían el criterio centralista reservado al Estado no sólo las relaciones internacionales y con la Comunidad Económica Europea, sino también la ejecución de los actos comunitarios, la Corte Costituzionale en su sentencia 142/1972, de 24 de julio, abrió nuevos horizontes para las Regiones en este campo, al

(18) Distintos proyectos de Ley a iniciativa de las Regiones y otros intentos de configurar un sistema de participación de las Regiones en la formación del Derecho comunitario pueden verse en ANDREU I Fornos, Esther: «Las Regiones italianas y la Comunidad Europea», en La aplicación .... cit., pp. 141-145.

(19) Condorelli, Luigl: «Les compétences des régions: l'experience italienne», Revue française d'Administration publíque, núm. 34, avril-juin, 1985, p. 277. 
señalar los requisitos que debían darse para poder traspasar a estos entes de la potestad que les permitiera regular materias de su competencia sobre las que se hubieran contraído compromisos comunitarios.

Como vemos, pues, la cuestión para la Corte Costituzionale no estriba ya en la competencia exclusiva estatal en materia de relaciones internacionales, como señalaba en sus anteriores pronunciamientos de la década de los 70 , sino que, ahora, la cuestión está en la existencia de garantías que permitieran al Estado asegurar el cumplimiento de las obligaciones comunitarias.

La Ley $382 / 1975$ y el DPR $616 / 1977$ citados, asumen y recogen estos pronunciamientos de la Corte Costituzionale estableciendo se transfiera a las Regiones la función de ejecución de los reglamentos y directivas comunitarias sobre las materias transferidas por el DPR 616, si bien en el caso de las directivas las Regiones del Estatuto ordinario deberán seguir, para la aplicación de las mismas, las normas de principio fijadas por el Estado mediante Ley; no ocurre lo mismo con las Regiones de Estatuto especial, al menos, en el ejercicio de sus competencias exclusivas, puesto que podrán desarrollar directamente las directamente comunitarias sin necesidad de esperar a la Ley estatal de principios alguna.

De otro lado, las normas citadas, concretamente el artículo 6 del DPR 616/1977 (20), contiene toda una serie de requisitos, un sistema de garantías (que era lo que exigía la mencionada en último término sentencia de la Corte Costituzionale) para los supuestos en que las Regiones no cumplieran las obligaciones comunitarias. Así, si una Región no ejecutare normativamente la directiva comunitaria se aplicaría directamente la Ley de principios directivas por el Estado. Si la Región incumpliera reiteradamente los compromisos comunitarios, el Gobierno, tras deliberación del Consejo de Ministros, con el dictamen de la Comisión parlamentaria de Asuntos Regionales, y oída la Región, puede fijar un plazo para que éste lleve a cabo la ejecución de la norma comunitaria, y si transcurrido el mencionado plazo la Región no ejecutara, el Consejo de Ministros sustituirá a la Región y procederá a la ejecución.

Este es, en definitiva y brevemente expuesto, el sistema de participación de las Regiones en el Derecho comunitario. Como fácilmente puede desprenderse, es un sistema, a mi juicio, absolutamente insatisfactorio para las aspiraciones regionales, puesto que prácticamente se niegà, de primeras, su participación en la creación

(20) Un comenario a este artículo puede verse en «comento al Decreto 616», ENZO CAPACCIOLI y Filippo Satta, Giuffrè, Milano, 1980. 
del ordenamiento jurídico comunitario y en la formación de las políticas comunes. Unica y exclusivamente son consultadas en el seno de la Conferencia Estado-Regiones, pero sus opiniones no vinculan al Estado. Y, por lo que se refiere a la ejecución del Derecho comunitario hay que señalar, de un lado, que si se lee con detenimiento el DPR 616 nos daremos cuenta que son muchas las funciones administrativas, las funciones de ejecución que, sobre las materias competencia de las Regiones, se han reservado al Estado, con lo cual resulta que el campo de actuación regional ha quedado considerablemente reducido. $Y$, de otro lado, que las medidas de sustitución previstas para los supuestos de falta de actividad o incumplimiento de las obligaciones comunitarias por las Regiones hace que éstas caigan en una especie de "desidia» en su papel de ejecutoras de la normativa comunitaria. Si el Estado con sus normas de principios ya desarrolla, por lo menos para las Regiones de Estatuto ordinario, las directivas comunitarias, parece evidente 0 , cuando menos, explicable que éstas no se «molesten» en realizar un trabajo que les viene dado por el Estado, y se limiten a aplicar la norma estatal que desarrolla la directiva comunitaria.

El tema, como puede apreciarse, no resulta pacífico. Las Regiones continúan presionando y reclamando un derecho de participación en el Derecho comunitario. Quizá la solución podría estar, como apunta Ciavarini Azzi (21), en una participación de las Regiones en el estadio de las negociaciones de las medidas comunitarias, que, como conocemos, no es el caso actual.

Digamos, para terminar este epígrafe dedicado al sistema de participación de las Regiones italianas en el Derecho comunitario, que éstas no pueden participar de forma directa en los que ANDREU I Fornos denomina «actividades de alcance comunitario (22), esto es, ningún representante de las Regiones acompaña a la delegación estatal y mucho menos las autoridades regionales pueden mantener contactos directos con las autoridades comunitarias, sino sólo, y en virtud de lo establecido en el artículo 4.2 del DPR 616/1977, en «actividades de promoción hacia el extranjero» $y$ «previo acuerdo con el Gobierno".

\section{EL REINO DE BELGICA: UN SISTEMA DE PARTICIPACION NO INSTITUCIONALIZADO}

El caso que vamos a analizar a continuación es algo peculiar. En Bélgica, a diferencia de los países analizados en los epígrafes

(21) Ciavarini Azzı, Guuseppe: L'application ..., cit., p. 199

(22) Andreu I Fornos, E.: Las Regiones italianas ..., cit., p. 150. 
anteriores, el proceso de descentralización se ha producido siendo ya este país miembro de las Comunidades Europeas desde su creación.

Las reformas constitucionales de 1979 y 1989 ha supuesto la creación de dos tipos de poderes públicos autónomos: las Comunidades y las Regiones, lo que ha significado una distribución interna del poder, bastante sui generis - como lo califica Pérez Tremps (23)-, entre el Estado, las Comunidades y las Regiones. Como es sabido, el constituyente de 1970 procedió a dos divisiones regionales diferentes reflejadas en el artículo 3 ter, en virtud del cual se crean las Comunidades francesa, flamenca y germanófona, y el artículo 107 quater, ambos del texto constitucional, por el que se crean las Regiones valona, flamenca y bruxelense. Pero, como ha señalado DalmaU I OrIOL (24), va a ser la reforma constitucional de 1980 la que perfila de modo definitivo las nuevas estructuras del Estado, concretadas en la Ley sobre reformas institucionales de 8 de agosto de 1980.

Antes de adentrarnos en el verdadero objeto de nuestro trabajo, digamos que en este sistema constitucional reciente (25) y cada Comunidad y cada Región disponen de sus instituciones (26) y competencias propias. De modo sintético, y por lo que hace referencia a las competencias de estos entes públicos, señalamos que las Comunidades ostentan competencias en materias culturales y lingüísticas (art. 59 bis de la Constitución), mientras que las Regiones gozan de competencias en materias económicas. Así, en virtud del artículo 6 de la Ley sobre reformas institucionales de 8 de agosto las Regiones son competentes en materia de urbanismo y ordenación del territorio, protección del medio ambiente, vivienda, planificación regional, política energética, etc., se trata, pues, como vemos, de un «regionalismo cultural», por un lado, y un «regionalismo económico», de otro.

Pues bien, expuesto esto y entrando ya en el análisis de la participación de las Comunidades y Regiones en el Derecho comunitario, lo primero que tenemos que destacar de modo principal es que, pese a que el Reino de Bélgica ya fuera, como señalamos, miembro de la Comunidad Europea casi veinte años antes de iniciar su proceso descentralizador, ni la Constitución ni las leyes han previsto sistema

(23) Perez Tremps, P.: Comunidades Autónomas ..., cit., p. 56.

(24) Dalmau I Oriol, Casimir de: «La aplicación del Derecho comunitario por las Comunidades y Regiones en Bélgica», en La aplicación ..., cit., p. 162.

(25) Sobre el sistema constitucional belga Vid. Delperee, Francis: Droit constitutionnel, T. I., F. Larcier, Bruselas, 1980, especialmente p. 239 y ss.

(26) En cada Comunidad y en cada Región existe un Consejo y un Ejecutivo que ejercen, respectivamente, funciones legislativas y ejecutivas. Vid. Título III, capítulos II y III de la Ley especial de 8 de agosto de 1980 . 
alguno de participación de estos entes en la formación y ejecución del ordenamiento jurídico comunitario. Es más, como ha apuntado Ciavarini AzZI (27), Bélgica es actualmente el país que más dificultades tiene con la mise en oeuvre (para emplear un término comunitario) de las directivas europeas.

Por lo que respecta a la fase que denominamos «ascendente», no existe mecanismo institucional alguno que asegure la participación de las Comunidades y Regiones en la formación de la voluntad estatal. En la práctica las Comunidades y Regiones son llamadas por el Ministerio de Asuntos Exteriores a participar en el seno de las reuniones de la "coordinación europea», órgano encargado de la preparación de la posición belga. $\mathrm{O}$, incluso, ya a nivel político, en el Comité Ministériel des Relations Extérieures (CMRE). Pero lo cierto es que, finalmente, las Comunidades y Regiones no son informadas de cuál es, tras este proceso, la posición belga en las Comunidades Europeas ni saben en qué medida sus opiniones, sus puntos de vista han sido tenidos en cuenta por el Gobierno nacional a la hora de fijar su postura. Por supuesto, si no son informadas ni conocen cómo o en qué ha sido recogido su parecer, mucho menos vinculan al Estado sus opiniones (28).

Distintos Comités (Etat-Communautés-Regions) se han creado como intento de institucionalización de un sistema de participación en la formación del Derecho comunitario de estos entes subestatales (29). Pero ninguno ha funcionado y, por tanto, no existe una real cooperación entre las instituciones nacionales, comunitarias y regionales. La posición belga ante las Comunidades Europeas es, en definitiva, adoptada solamente por el Estado, la instancia central.

Refiriéndonos ya a la fase de ejecución de la normativa y las políticas comunitarias, señalemos que la cuestión, al menos a nivel teórico, es de menor importancia. Como ha señalado JADOT (30), la cuestión de nivel de poder competente para la ejecución del Derecho europeo es una cuestión de Derecho interno, lo que significa, como tuvimos ocasión de ver en la República Federal de Alemania que si la Comunidad o Región es competente en una materia determinada, es ella quien tiene el título competencial para ejecutar las obligaciones

(27) Ciavarini AzzI, G.: L'application ..., cit., p. 200.

(28) Sur, Erik: «La collaboration de l'Etat, des communautes et des regions dans le domaine de la politique exterieure: les Communautes Europeennes", en La collaboration..., cit., pp. 71-72.

(29) Así, podemos citar el Comité ministerial de coordinación Relaciones ExterioresComunidades/Regiones o el Comité de Política europea CEE. Estado-Regiones-Comunidades. Como nos aporta el dato Sur en su op. cit., el primero de los mencionados Comités durante la primera legislatura 1985-1987 se ha reunido en una sola ocasión y el segundo desde abril de 1984 no se ha reunido. Vid., p. 72.

(30) JADOT, BENOIT: «L'execution du droit europeen par les regions», en La collaboration..., cit., p. 128. 
comunitarias en dicha materia. Así lo ha refrendado, de otro lado, el Conseil d'Etat.

No obstante, si se trata de una competencia compartida, se crea un grupo de trabajo Estado-Comunidades o Estado-Regiones, según se trate de una materia cultural o económica, que tiene como objetivo coordinar las medidas de aplicación de la normativa comunitaria sobre dicha materia.

Por último, tratemos de la participación directa de las Comunidades y Regiones en las Comunidades Europeas, en sus instituciones, donde se produce un hecho peculiar.

Las Comunidades participan en las reuniones de los órganos comunitarios cuando se tratan asuntos que son de competencia exclusiva (culturales, educativas y personalizables). Esta participación no está institucionalizada, pero se produce en la práctica. Se trata, como dice Dalmau i Oriol, de un «pacto de caballeros», que no tiene ningún carácter oficial (31), pero que hace que en los Consejos de Ministros de Cultura la delegación belga esté integrada única $y$ exclusivamente por los representantes de las Comunidades francesa, flamenca y germanófona, sin asistencia de ningún representante del aparato central del Estado.

Las Regiones también asisten a las reuniones de los órganos e instituciones comunitarias cuando se debaten asuntos que afectan a sus competencias exclusivas, pero, al contrario que las Comunidades, no sólo ellas, sino integradas en la delegación estatal belga.

\section{EL REINO DE ESPAÑA: INTENTOS Y PROYECTOS}

Como señalábamos al principio de este trabajo, también las Comunidades Autónomas aspiran a participar en la formación y ejecución del Derecho comunitario. Pues bien, dedicaremos este último epígrafe a explicar y analizar qué se ha hecho, o se está haciendo, en nuestro país para dar respuesta a estas exigencias autonómicas de participación en el Derecho europeo. Y, también, a plantear algunas posibilidades, algunas soluciones para que las Comunidades Autónomas vean satisfechas sus demandas.

No obstante, antes de entrar en el núcleo de la exposición, señalemos que la vía que parece más adecuada para establecer un proceso de este tipo es la de la colaboración o cooperación entre el Estado y las Comunidades Autónomas. En esta idea tanto la doctrina

(31) Dalmau i Oriol, C.: La aplicación ..., cit., p. 189. 
jurídica española (32) como los políticos - centrales y autonómicosparecen estar de acuerdo; baste, por lo que respecta a estos últimos, si no, repasar los debates sobre el estado de las Autonomías que se han producido en los últimos años, así como las sesiones de la Comisión Mixta para las Comunidades Europeas.

Manifestamos, de idéntico modo, que la figura o el instrumento jurídico más idóneo para llevar a cabo esta colaboración entre ambas instancias políticas es el convenio. Pero, como es de todos conocido, nuestro texto fundamental $y$, en general, nuestro ordenamiento jurídico ha sido extraordinariamente parco en esta materia. Tan sólo un precepto constitucional -el artículo 145.2- se refiere a los convenios y acuerdos de cooperación, aunque limitándolos a las Comunidades Autónomas entre sí, esto es, a la denominada cooperación horizontal (33). Nada se dice expresamente, por el contrario, sobre las posibilidades de cooperación vertical, es decir, la que puede darse entre el Estado y las Comunidades Autónomas. Sin embargo, esto es algo que debe considerarse implícito en la propia esencia de la forma de organización territorial del Estado, en la esencia propia del llamado por muchos «Estado de las Autonomías» y que no resulta preciso justificarlo en preceptos concretos, podríamos decir parafraseando al Tribunal Constitucional (34).

Dicho esto, adentrémonos en el verdadero objeto de este epígrafe exponiendo, en primer término, qué es lo que hasta el momento se ha hecho en este campo de la participación de las Comunidades Autónomas en el ordenamiento jurídico comunitario $y$, en segundo lugar, planteando algunas otras formas de participación perfectamente posibles en nuestro entramado jurídico constitucional.

\section{Los proyectos de convenios de cooperación entre el Gobierno de la Nación y las Comunidades Autónomas sobre los asuntos relacionados con las Comunidades Europeas}

Tenemos conocimiento hasta el día de hoy de tres proyectos de convenios entre el Gobierno de la Nación y las Comunidades Autónomas sobre cooperación en los asuntos relacionados con las Comunidades Europeas:

(32) Vid. por todos Muñoz Machado. Santiago: El Estado, el Derecho interno y la Comunidad Europea, Civitas, Madrid, 1986, pp. 87-90.

(33) En este sentido Rodriguez-Zapata y Perez, Jorge: «Artículo 145. Convenios entre Comunidades Autónomas», en Constitución española de 1978, T. XI, dirigido por O. Alzaga, Edersa, Madrid, 1988, p. 69.

(34) Vid. Sentencia del Tribunal Constitucional número 18, de 4 de mayo de 1982, BJC. 
- El primero es de 1985, antes de nuestro ingreso en la Comunidad Europea (35).

- El segundo, de 1986, que por diversos acontecimientos políticos (discusión de un nuevo sistema de financiación de las Comunidades Autónomas de régimen común y convocatoria de nuevas elecciones generales) no llegó a ver la luz. No obstante, por las noticias que tenemos, no difería en mucho del primero; tan sólo recogía algunas propuestas presentadas por las Comunidades Autónomas.

- El tercero, de 1987, del que solamente conocemos sus líneas maestras anunciadas por el Ministro de Administraciones públicas en una comparecencia ante la Comisión Mixta para las Comunidades Europeas (36).

Por lo que respecta a la fase «descendente», es decir, de desarrollo y ejecución del Derecho comunitario se sigue la regla de respetar el sistema de distribución de competencias establecido por nuestro texto constitucional, fundamentalmente en sus artículos 148 y 149; de manera tal que será el Estado o las Comunidades Autónomas quienes desarrollarán normativamente o ejecutarán administrativamente el ordenamiento jurídico comunitario según quien tenga asumida la competencia sobre la materia de que se trate.

Este criterio, además, se ha visto recientemente confirmado por el Tribunal Constitucional en su sentencia 252/1988, de 20 de diciembre, cuando refiriéndose a la ejecución de las directivas comunitarias manifiesta: «Por consiguiente, son las reglas internas de delimitación competencial las que deben determinar a quién corresponde la ejecución de las directivas comunitarias» (37).

El proyecto de convenio de 1985 hizo especial hincapié sobre esta fase por ser, en ese momento, la que más preocupaba ante el inminente ingreso de España en la Comunidad Europea y las dificultades de adaptación que se preveían. El proyecto, mejor dicho, los «principios básicos» del proyecto de convenio, en expresión del Ministerio de Administraciones Públicas (38), de 1987, por el contrario, parece que van a dedicar poca atención a esta cuestión de la ejecución del Derecho comunitario, habida cuenta ya de nuestra experiencia en las Comunidades Europeas.

(35) Texto mecanografiado del Ministerio de Administración Territorial.

(36) Diario de Sesiones del Congreso, núm. 58, de 3 de febrero de 1987.

(37) Sobre la sentencia citada verse Sainz Moreno, Fernando: «El principio de unidad del orden económico y su aplicación por la jurisprudencia constitucional», en Pasado, presente y futuro de las Comunidades Autónomas, dirigido por Sebastián Martín Retortillo, IEEE, Madrid, 1989, pp. 386-389.

(38) DSC, cit., p. 2281 
Justamente ocurre lo contrario por lo que se refiere a la fase de participación de las Comunidades Autónomas en la formación de la voluntad estatal, esto es, la fase que denominamos "ascendente».

Mientras el proyecto de convenio de 1985 se limitaba a manifestar que el Gobierno de la Nación «procurará» incorporar los criterios y posiciones de las Comunidades Autónomas o que "procurará" incorporar las observaciones de las Comunidades Autónomas a las propuestas que se formulen ante los órganos comunitarios, parece ser -así se desprende de las palabras del señor Ministro--, que en el nuevo proyecto de convenio se sustituirá este término de "procurará" por el de «deberá», expresándose así un auténtico compromiso, una auténtica obligación de la participación de las Comunidades Autónomas en la formación de la voluntad estatal que se expresará en Bruselas.

Para llegar a esta voluntad estatal, fruto de las opiniones de las Comunidades Autónomas y del Gobierno de la Nación, y para resolver discrepancias y adoptar criterios comunes, se potenciarán las Conferencias Sectoriales reguladas en el artículo 4 de la Ley del Proceso Autonómico - más necesarias que nunca en expresión del señor Ministro- como órganos de encuentro y cooperación no sólo para construir una voluntad unitaria que el representante de España defienda ante las instituciones comunitarias, sino también para discutir en su seno los problemas de ejecución y desarrollo del Derecho y las políticas comunitarias (39).

También se prevé en el proyecto de convenio de las Comunidades Autónomas tengan una representación directa ante los órganos e instituciones comunitarias y para ello se propone, como instrumento de cooperación y cauce de la información emanada de las Comunidades Europeas, la creación del «Observador de las Comunidades Autónomas», órgano unipersonal representante de estos entes subestatales $y$, por tanto, designado por los mismos, que se integraría en la Representación Permanente de España en la Comunidad Europea.

Como fácilmente puede observarse, y así lo declaró, además, el Presidente del Gobierno en el debate de investidura producido tras las elecciones generales de 1986, este modelo de participación de las Comunidades Autónomas en el Derecho comunitario está claramente inspirado en el modelo de la República Federal de Alemania, pero en

(39) En la conferencia de Vicepresidentes de las Comunidades Autónomas, reunidas en dos ocasiones, se han abordado, entre otras, la cuestión de las consecuencias que sobre las Comunidades Autónomas puede tener el ingreso de España en las Comunidades Europeas, el estudio de las medidas pertinentes en orden a hacer fluido el intercambio de información entre las distintas Administraciones, etc., tomo el dato de Perez Calvo, Alberto: «Actuaciones de cooperación y coordinación entre el Estado y las Comunidades Autónomas», en Simposio Internacional de Derecho autonómico, Generalitat Valenciana, Valencia, 1988, p. 285. 
el modelo del Acuerdo de 1979, no en el vigente de 1986, que, anteriormente, hemos tenido ocasión de estudiar.

Las críticas que pueden hacerse al modelo diseñado en este proyecto de convenio de 1987 son prácticamente las mismas que los Länder alemanes hicieron al suyo y que supusieron la modificación del mismo. La complejidad y dificultad en el proceso de adopción de decisiones se nos antoja grandísima. La lentitud del mismo para llegar a una opinión común 18 partes, igualmente, nos parece importante, de manera tal que, pensamos, muchos asuntos serán discutidos en las instituciones comunitarias sin que haya llegado a producir esa voluntad unitaria del Estado español. La regla de la unanimidad que, suponemos, será la que funcione en las Conferencias Sectoriales será muy poco operativa, amén, como ya señalamos más arriba, de poco democrática; y, como manifestó el Ministro de Administraciones públicas en su comparecencia ante la Comisión Mixta para las Comunidades Europeas, la Comunidad tiene su ritmo y ningún país puede pretender frenarlo, salvo que esté dispuesto a soportar más adelante las consecuencias.

Ahora bien, entiendo que mejor es la formulación de este proceso que la nada que existe en la actualidad en este campo. Mejor es que se establezca un sistema en el que las Comunidades Autónomas pueden hacer oír su voz y manifestar sus opiniones; un sistema que permita una información abundante y rápida de lo que ocurre en las instituciones comunitarias, que no la situación actual donde la picaresca - obligada- de las Comunidades Autónomas es la que permite su presencia en Bruselas y todo lo que ello conlleva.

\section{Algunos instrumentos más de participación}

Además de lo expuesto en el proyecto de convenio de 1987 pocas posibilidades más, pocos instrumentos más ofrece nuestro actual ordenamiento jurídico constitucional. Si acaso señala alguna idea más que pudiera servir para potenciar la efectiva participación de las Comunidades Autónomas en el Derecho y en las políticas comunitarias.

Una primera idea, otro instrumento más que el proyecto de convenio de 1987 no recoge y que, sin embargo, si se halla previsto en el modelo en que el Ministerio se ha inspirado, es la presencia directa de representantes de las Comunidades Autónomas, integrados en la delegación española, en los comités asesores y consultivos de la Comisión y del Consejo.

Estimamos positivo y conveniente que las Comunidades Autónomas tengan conocimiento y participen desde el primer momento en cuantos asuntos, que afecten a sus competencias, se sometan a las 
instituciones comunitarias. De este modo, la información y la participación sería más amplia, lo que daría lugar a estar en mejor posición a la hora de tomar una decisión y el papel que desempeñarían sería también más activo.

Otra posibilidad más de participación de las Comunidades Autónomas pudiera ser a través de los Grupos Territoriales del Senado. Ya que en su momento «se perdió la ocasión» de hacer del Senado una auténtica Cámara de representación territorial quizás, a través de estos Grupos Territoriales regulados en el artículo 32 del Reglamento del Senado las Comunidades Autónomas podrían hacer oír su voz y participar, cuando menos, en el desarrollo y ejecución del Derecho comunitario que correspondiera al Estado a través de las Cortes Generales.

No obstante, hay que confesar que esta última vía resulta muy pobre. Nunca podría ser la decisiva, aunque sí complementaria de las otras que pudieran adoptarse. $Y$, estimo que lo que verdaderamente habría que hacer sería propugnar una reforma del Senado como auténtica y verdadera Cámara de representación de las «nacionalidades y regiones» que integran la nación española que, además, recordémoslo, también son Estado.

\section{Recapitulación}

Dicho esto, tan sólo nos resta recapitular sobre la participación de las Comunidades Autónomas en el Derecho comunitario para exponer no ya los intentos y proyectos, sino la fiel realidad, el cómo está hoy mismo esta cuestión.

No muchos espacios necesitamos para hacer esta exposición, algo, por otro lado, que se desprende de lo manifestado con anterioridad.

Por lo que se refiere a la fase "ascendente» nada hay. Las Comunidades Autónomas no participan en la formación de la voluntad estatal, no coadyuvan en la preparación de la posición española que se manifiesta en Bruselas. O, dicho en otros términos, la única postura que ante los órganos e instituciones comunitarias se expone en todo tipo de asuntos, afecten o no a las competencias de las Comunidades Autónomas, es la de los órganos centrales del Estado. Ni se pide, ni se escucha el parecer de las Comunidades Autónomas sobre los denominados «asuntos comunitarios». Esto es algo que, a mi juicio, precisa ser corregido con prontitud.

Por lo que respecta a la fase denominada «descendente» ya lo hemos señalado en páginas anteriores. Al menos, desde un punto de vista teórico no se plantea problema alguno, se sigue el criterio de 
respetar el orden constitucional interno de distribución de competencias entre el Estado y las Comunidades Autónomas; de tal manera, repetimos, que será uno $u$ otro ente quien ejecute, tanto normativa como administrativamente, el ordenamiento jurídico comunitario según tenga atribuida la competencia sobre la materia de que se trate.

Finalmente, manifestemos que las Comunidades Autónomas carecen de representación alguna ante los órganos e instituciones comunitarias. Ni integrados en la delegación española ni fuera de ella, ni siquiera en órganos que tanto afectan a las regiones como en el caso del FEDER (40). Esto, evidentemente, también debe ser corregido a la mayor brevedad posible.

Estimamos que la situación que acabamos de describir de ningún modo puede mantenerse. A mi juicio, se está olvidando a una parte importante del Estado como son las Comunidades Autónomas, vulnerándose de este modo el principio de autonomía que, como ha señalado el Tribunal Constitucional (41), junto con el principio de unidad conforman los dos grandes principios sobre los que se asienta la «arquitectura entera del Estado».

El sistema de «autonomismo cooperativo», podríamos decir, que ha perfilado nuestro texto constitucional, según un importante sector doctrinal (42) exige la participación, la colaboración, la coordinación, el deber de información recíproca, etc., en éste, así como en otros muchos campos. Ningún obstáculo existe, desde el punto de vista jurídico-constitucional, para responder a esta aspiración de las Comunidades Autónomas como numerosos autores se han encargado de demostrarlo muy acertadamente (43); antes, al contrario, opino que constituye una obligación constitucional de los Poderes públicos de que tratamos. Sólo falta la voluntad política de cumplir con esta exigencia constitucional.

(40) No olvidamos la Decisión 88/487/CEE de la Comisión de 24 de junio de 1988 (DOCE serie L 247, de 6 de septiembre de 1988) que ha creado el Consejo Consultivo de los entes regionales y locales, pero se trata de un órgano creado por la propia Comunidad Europea, no por el Estado.

(41) Sentencia del Tribunal Constitucional de 2 de febrero de 1981 BJ Co, núm. 1, mayo, 1981

(42) Vid., por todos, Garcia de Enterria, Eduardo: Estudios sobre autonomias territoriales, Civitas, Madrid, 1985.

(43) Por todos, Muñoz Machado, S.: El Estado ..., cit., pp. 82-87. 
